\title{
Gravity observations on Santorini island (Greece): Historical and recent campaigns
}

\author{
Melissinos PARASKEVAS ${ }^{1, *}(\mathbb{D})$, Demitris PARADISSIS ${ }^{1}$, \\ Konstantinos RAPTAKIS ${ }^{1}$ (D), Paraskevi NOMIKOU ${ }^{2}$ (D), \\ Emilie HOOFT ${ }^{3}$ iD, Konstantina BEJELOU ${ }^{2}$ (D) \\ ${ }^{1}$ Dionysos Satellite Observatory, National Technical University of Athens, \\ Polytechneioupoli Zografou, 15780 Athens, Greece, \\ e-mail: melipara1@yahoo.gr, dempar@central.ntua.gr, corapt@central.ntua.gr \\ ${ }^{2}$ Department of Geology and Geoenvironment, National and Kapodistrian University \\ of Athens, Panepistimioupoli Zografou, 15784 Athens, Greece, \\ e-mail: evinom@geol.uoa.gr, bejelouk@gmail.com \\ ${ }^{3}$ Department of Earth Sciences, University of Oregon, \\ OR 97403, Eugene, USA; e-mail: emilie@uoregon.edu
}

\begin{abstract}
Santorini is located in the central part of the Hellenic Volcanic Arc (South Aegean Sea) and is well known for the Late-Bronze-Age "Minoan" eruption that may have been responsible for the decline of the great Minoan civilization on the island of Crete. To use gravity to probe the internal structure of the volcano and to determine whether there are temporal variations in gravity due to near surface changes, we construct two gravity maps. Dionysos Satellite Observatory (DSO) of the National Technical University of Athens (NTUA) carried out terrestrial gravity measurements in December 2012 and in September 2014 at selected locations on Thera, Nea Kameni, Palea Kameni, Therasia, Aspronisi and Christiana islands. Absolute gravity values were calculated using raw gravity data at every station for all datasets. The results were compared with gravity measurements performed in July 1976 by DSO/NTUA and absolute gravity values derived from the Hellenic Military Geographical Service (HMGS) and other sources. Marine gravity data that were collected during the PROTEUS project in November and December 2015 fill between the land gravity datasets. An appropriate Digital Elevation Model (DEM) with topographic and bathymetric data was also produced. Finally, based on the two combined datasets (one for 2012-2014 and one for the 1970s), Free air and complete Bouguer gravity anomaly maps were produced following the appropriate data corrections and reductions. The pattern of complete Bouguer gravity anomaly maps was consistent with seismological results within the caldera. Finally from the comparison of the measurements made at the same place, we found that, within the caldera, the inner process of the volcano is ongoing both before, and after, the unrest period of 2011-2012.
\end{abstract}

Key words: Santorini, gravity, Bouguer, Free Air Anomaly, HMGS

\footnotetext{
${ }^{*}$ corresponding author: e-mail: melipara1@yahoo.gr
} 


\section{Introduction}

Earth's gravity is a physical force resulting from the gravitational attraction due to the planet's mass and a centrifugal term due to Earth's rotation. Geophysicists use gravity to better understand deep structures of the Earth by modelling their density distributions with depth. Gravity variations result from a variety of processes including variations in: elevation, mean density of an area, latitude, and/or the particular time measurements were made. At volcanos, careful analysis of temporal variations in gravity can be used to identify changes in the near-surface volcanic system (e.g. Battaglia et al., 2008; Williams-Jones et al., 2008; Vajda, 2016).

Santorini volcanic complex is located in the central part of the Hellenic Volcanic Arc (South Aegean Sea) (Fig. 1), and consists of Thira (Santorini), Palea Kameni, Nea Kameni, Aspronisi, Thirassia and the active submarine volcano of Kolumbo. Santorini is also well known for the Late-Bronze-Age "Minoan" eruption that might have been responsible for the decline of the great Minoan civilization on the island of Crete. The volcano was in a quiet, rest period from 1950 to 2011. In January 2011, Santorini entered a phase of unrest, which lasted until March 2012 (e.g. Parks et al., 2012; Newman et al., 2012). Onshore measurements of the gravitational field were carried out after the unrest period in December 2012 (Fig. 1d) and September 2014 (Fig. 1e) as discussed by Paraskevas et al. (2014; 2019). To probe the gravity field prior to the unrest period, Dionysus Satellite Observatory of National Technical University of Athens (DSO/NTUA) obtained a set of measurements for Santorini island, that has existed since 1976 (AgatzaBalodimou and Papazissi, 1984) (Fig. 1b). Furthermore, a 1969 gravity dataset from Yokoyama and Bonasia (1978) (Fig. 1a) and gravity values from the Hellenic Military Geographical Service (HMGS) (Fig. 1c) were integrated with the national gravity network at various times. In addition, offshore gravity data were collected during the PROTEUS project in November and December 2015 (Hooft et al., 2015) (Fig. 1f).

The aim of this paper is to make two gravity maps for the Santorini volcanic group (Thira, Thirassia, Palea and Nea Kameni and Aspronisi) that are adjusted to a comparable gravity datum. One map represents the period prior to the Santorini unrest in 2011-2012 and includes data from the 1970s. The second map is for the years following the unrest period and includes data from 2012-2014. 


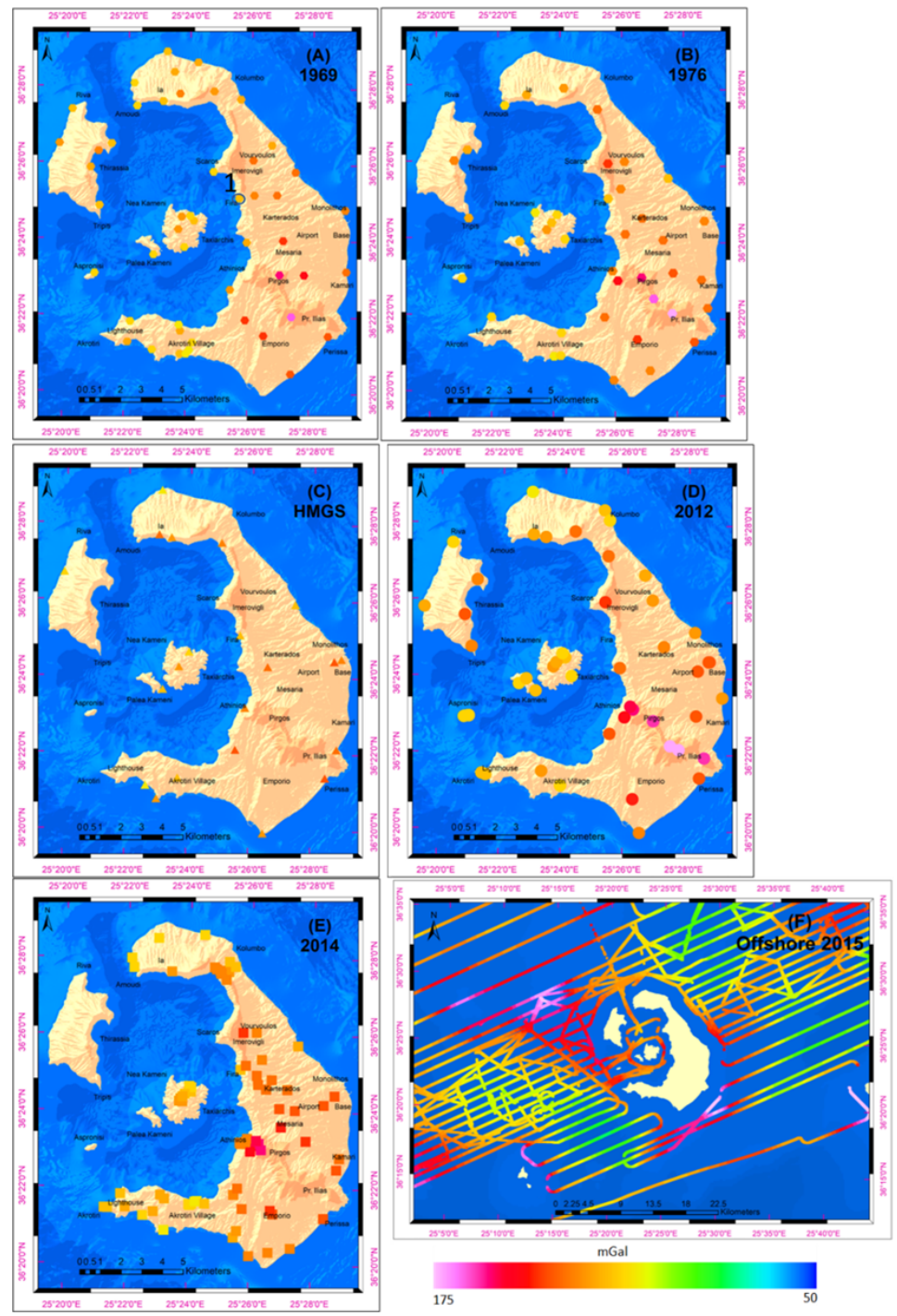

Fig. 1. It shows the spatial distribution of Free Air Anomalies of all datasets overlaying a produced terrain-bathymetry model. (a) 50 station refer to station 1 (Fira) after Yokohama and Bonasia (1978), (b) 41 stations refer to Piraeus port after Agatza-Balodimou and Papazissi (1984), (c) 20 stations graded by HMGS refer to old National Gravity Station, (d) 53 stations refer to HMGS after Paraskevas et al. (2014; 2019), (e) 83 stations refer to HMGS after Paraskevas et al. (2014; 2019), (f) Offshore Gravity measurements refer to HMGS after Paraskevas et al. (2019). 


\section{Data and methods}

\section{A. Coordinate system}

The selected coordinate system for this research is WGS84 (G1674 edition). To be compatible with this system, every gravity measurement needs an appropriate transformation from the time of the measurement to the selected coordinate system. The datasets of 1976 and 1969 were picked from maps using Hayford geographic coordinates, while the more recent datasets were measured in the WGS84 geographic system. The accurate position of each station measured in 1976 and 1969 was calculated using a local transformation between the two systems and corrected with descriptions of each station. New geographic coordinates for stations measured in 1976 and 1969 were picked from orthophotos with accuracy better than $2 \mathrm{~m}$.

The gravity datum selected was the unpublished yet Local Hellenic Gravity Datum from HMGS (epoch 2014). Datasets of 1976 and 1969 were shifted to a proper reference station to correspond to the selected gravity datum. Gravity values that refer to the Potsdam gravity datum were transformed to the IGSN71 gravity network subtracting $14.88410^{-5} \mathrm{~m} / \mathrm{s}^{2}$ (mGal), which is the measured difference between the National Gravity Station in HMGS and IGSN71.

\section{B. Earth and ocean tides}

Earth tides for the dataset of 1969 and benchmarks graded from HGMS were calculated using Longman's Formula (Longman, 1959) with estimated accuracy of $4-5 \mu \mathrm{Gal}$ as shown by $Y u$ et al. (2019). For gravity datasets with raw gravity measurements $(1976,2012,2014)$, Earth and ocean tides were corrected using an unpublished MATLAB code that includes IERS treaties (International Earth Rotation and Reference Systems Service) (Petit and Luzum, 2010), precise ephemeris from https://www.jpl.nasa.gov/ and the ocean model FES2004 (Lyard et al., 2006). The functions of the code were described by Papanikolaou (2012).

\section{Onshore gravity datasets}

\section{Gravity survey of 1969}

Yokohama and Bonasia (1978) carried out a gravity survey at 50 stations 
(Fig. 1a). Their results are available at the Bureau Gravimetrique International $(B G I)$. These measurements were also included in the HMGS report of 1976. The standard deviation of each measurement was better than $0.060 \mathrm{mGal}$ and all measurements referred to the base station of Santorini island at Fira port, which was included in the old National Gravity Network, with a reported difference from station 1 (Fig. 1a) of $0.127 \mathrm{mGal}$. For this study, the absolute gravity values refer to the Potsdam base station and were transformed to the IGSN 71 reference network and from there to the selected gravity datum. Reported elevations of each station were measured using barometers and psychrometers, so their accuracy is probably 1-2 metres. New elevations for every measurements were used in this research using the produced 5 metre-DEM (Paraskevas et al., 2014).

\section{Gravity survey of 1976}

In 1976, Agatza-Balodimou and Papazissi (1984) from the National Technical University of Athens (NTUA) carried out a series of measurements on Santorini island using La Coste \& Romberg G51 and G63 gravimeters (Fig. 1b). Besides that, three Thomson altimeters and one Assman psychrometer were used to obtain altitude information. Detailed descriptions of each benchmark study were used to improve their location and elevation.

This gravity campaign was connected, via Piraeus' port, to two base gravity stations at the NTUA (School of Architecture in Athens and Department of Topography in Zografou) to determine absolute gravity values. The adjusted gravity difference from these stations to the National Gravity Station of HMGS was used to reference all measurements to the same datum.

During data processing, raw measurements were corrected for a reading factor (according to La Coste \& Romberg recommendation table) and for the Earth tide effect (Papanikolaou, 2012). Finally, a linear approximation model was employed to correct for daily drift in the data. This campaign took place from 19/4/1976 to 2/5/1976 and it was carried out in nine day-loops. Corrected measurements for drift and tide effects were adjusted simultaneously using the least squares adjustment method (Torge, 1989) without weights. The resolution of these gravimeters ( $\mathrm{L} \& \mathrm{R}$ type $\mathrm{G})$, is $10 \mu \mathrm{Gal}$ and the best achievable accuracy is up to $15 \mu \mathrm{Gal}$ according to Seigel (1995). The resolution of the gravimeter $(10 \mu \mathrm{Gal})$ was added to 
the adjustments' standard deviation for each measurement. The derived precision (standard deviation) of the calculated absolute gravity values was 0.012 to $0.071 \mathrm{mGal}$ (Appendix 1).

\section{Various gravity surveys reported by HMGS}

HMGS carried out repeated gravity measurements in the Santorini area as part of a project that took place in 1966, 1969, and 1975 (Fig. 1c). All these measurements were made using 3 Lacoste \& Romberg gravimeters and one Worden gravimeter. The reported standard deviation (SDV) of these observations is between 0.011 and $0.049 \mathrm{mGal}$ and the absolute gravity values are referenced to the old HMGS gravity station. Gravity values were shifted to refer to National Gravity Station of HMGS (2014) by adding the measured difference between old and new National gravity station ( $\left.g_{\text {old National Gravity Station }}-g_{\text {new National Gravity Station }}=0.084 \mathrm{mGal}\right)$.

HMGS established and made repeated measurements at the gravity station near Santorini airport, which was one of the stations of the earliest campaign. This gravity station belongs to the First Order National Gravity Network, which implies that it is very accurate and its results remain stable for years. The most recent measurements for the First Order National Network were made in 2005. For these measurements 3 Lacoste \& Romberg gravimeters type $\mathrm{G}$ and one type $\mathrm{D}$ (resolution $0.001 \mathrm{mGal}$ ) were used. According to an unpublished HMGS First Order gravity stations report of 2015 the standard deviation for the Santorini station was $0.010 \mathrm{mGal}$ using 8 independent measurements.

\section{Gravity campaign of 2012}

In 2012 gravity measurements were collected using a Scintrex CG5 gravimeter. The observations include 53 stations (Fig. 1d) 36 of which are at known orthometric heights. Furthermore, a GPS Promark 100 receiver was used to measure elevation 3-5 metres around each benchmark.

The campaign took place from 10 to 16/12/2012 and was connected with the National Gravity Station of HMGS through the "El. Venizelos" airport, by repeated measurements with air transport. For every datum location, at least two successive measurements were taken to ensure repeatability. In addition, as it is essential in any precise gravity survey, nearly all stations were revisited several times, either on the same loop to check for drift, or 
on a different loop to tie loops together.

Final measurements were adjusted together by the least squares adjustment method (Torge, 1989) using as standard deviation of each measurement the recorded SDV of the appropriate gravimeter. The derived standard deviation (precision) of the calculated absolute gravity values was better than 0.016 to $0.037 \mathrm{mGal}$ (Appendix 2).

\section{Gravity campaign of 2014}

This campaign aimed to fill gaps in the 2012 measurements and was performed from 23 to $28 / 9 / 2014$ using the same instrumentation as in the campaign of 2012. The observations include 83 additional stations (Fig. 1e) and the measurements were connected to the National Gravity Station of HGMS through the Piraeus port control point, by repeated measurements with ship transport.

Gravimeter static drift was calculated offline before and after the campaign at the gravity station of DSO/NTUA using $24 \mathrm{~h}$ measurements. Earth tide effects for each station were calculated offline using the code of $P a$ panikolaou (2012), while all other available corrections were made using the software of the gravimeter (tilt, temperature correction, and seismic filter).

Final measurements were adjusted together by the least squares adjustment method (Torge, 1989) using as standard deviation (SDV) of each measurement the recorded SDV of the gravimeter. The derived standard deviation of the calculated absolute gravity values was better than 0.009 to $0.031 \mathrm{mGal}$ (Appendix 3).

\section{Offshore gravity measurements}

Marine gravity measurements were collected during the PROTEUS project (Hooft et al., 2015) in November and December 2015 using BGM-3 gravimeter (SN S224) on the R/V Marcus Langseth, cruise MGL1521, and are available from https://www.rvdata.us/ (Fig. 1f). Firstly, ship gravity data were merged with navigation data (date, time, ship's speed, water depth, course, latitude and longitude). The processing procedure also includes a Gaussian 240 second filter, a median filter of 480 seconds, a non-linear filter of 60 seconds, Eötvös Correction and tide correction. Measurements were adjusted to the National Gravity Station of HGMS through the Piraeus 
port. Long term static drift was calculated from relative gravity differences at Piraeus port in the beginning and at Heraklion port at the end of the campaign, using absolute gravity values of National gravity network. Calculated long term drift was $0.02 \mathrm{mGal} /$ day. Finally, crossover analysis and adjustment was applied (using the method of Hsu (1995)). The derived standard deviation of crossover adjusted values was better than $0.5 \mathrm{mGal}$.

\section{E. Digital Terrain Model and seafloor topography}

Various data were used to develop a detailed Digital Terrain Model that includes seafloor topography: (i) geometric altitudes from the NTUA network from 56 locations, (ii) a 5-metre DTM graded from the Hellenic Military Geographic Agency (HMGA) generated from combined photogrammetric methods and height measurements, (iii) orthometric and geometric heights at geodetic control points obtained by the HMGA, (iv) height measurements with GPS receivers, (v) $10 \mathrm{~m}$ seafloor contours derived from HMGA, (vi) high resolution swath data provided by Nomikou et al. (2014), (vii) the high resolution GDEM of ASTER v2 (NASA and METI, 2011), (viii) the recent coastline from HMGA and (ix) Lidar data from Nomikou et al. (2014). A dense Digital Elevation Model (DEM) with pixel size of $5 \mathrm{~m}$ was created in the area of interest and a rather rough DEM with pixel size of $100 \mathrm{~m}$ in the surrounding areas.

\section{F. Global Geopotential Model (GGM)}

Two GGM were tested in the area of this research: EGM2008 (Pavlis et al., 2012) and EIGEN6C4 (Förste et al., 2014), until order and degree 2190. These models were tested at 128 measured stations during the 2012-2014 campaigns, comparing measured free air gravity anomalies with calculated ones from GGM at the same point, using MATLAB code after Papanikolaou (2013). Table 1 shows that both GGM fit the measured data very well, compared to other areas at Greece (Papadopoulos et al., 2019). EGM2008 performed slightly better and consequently this is the selected GGM.

\section{G. Reduction scheme}

The reduction scheme for final adjusted absolute gravity values (Gabs) includes: 
Table 1. Comparison of GGMs in 128 gravity stations measured in 2012 and 2014 at Santorini complex.

\begin{tabular}{|c|c|c|}
\hline \multirow{2}{*}{ Statistics } & \multicolumn{2}{|c|}{128 gravity stations } \\
\cline { 2 - 3 } & EGM2008 [mGal] & EIGEN6C4 [mGal] \\
\hline Min & 6.04 & 26.63 \\
\hline Max & 69.08 & 87.81 \\
\hline Mean & 24.86 & 38.27 \\
\hline SDV & 11.34 & 13.04 \\
\hline
\end{tabular}

- Geographic latitude corrections (Normal gravity): Normal Gravity for all gravity data was calculated to WGS84 ellipsoid using the closed Somigliana's formula (Somigliana, 1930):

$$
G \bmod =g e * \frac{1+k \sin ^{2} \varphi}{\sqrt{1-e^{2} \sin ^{2} \varphi}},
$$

where Gmod is normal gravity at WGS84 ellipsoid, ge $=978032.67714$ $\mathrm{mGal}, k=0.00193185138639, e^{2}=0.00669437999013$, and $\varphi$ is the latitude of the station in decimal degrees (Hofmann-Wellenhof and Moritz, 2005).

- Free air reduction: The simply free air gradient was used:

$\delta g F A=-0.3086 H$,

where $H$ is the orthometric height above sea level in metres.

- Bouguer spherical cap: The Bouguer spherical cap models a simple mass from the ellipsoid to the station height. A simple Bouguer reduction was calculated using equation 3 (Hildenbrand et al., 2002):

$\delta g B C=2 \pi G \rho(\mu h-\lambda R)$,

where $G=6.674 \times 10^{-11} \mathrm{Nm}^{2} / \mathrm{kg}^{2}$ is the universal gravitational constant, $\rho$ is the mean density of the rock material of the plate (here $2670 \mathrm{~kg} / \mathrm{m}^{3}$ ), $\mu$ and $\lambda$ are dimensionless coefficients (LaFehr, 1991), $h$ is the height of the gravity station above the GRS80 reference ellipsoid $(\mathrm{km})$, and $R$ is the combined height of the gravity station and average radius of Earth $(\mathrm{km})$. 
- Terrain Correction (TC): Terrain correction was calculated using the algorithm proposed by Nagy (1966) and Kane (1962). To calculate corrections, the produced DTM5 was 'sampled' to a grid mesh centred on the station to be calculated. The correction was calculated based on near zone, intermediate zone, and far zone contributions. In the near zone, 0 to $5 \mathrm{~m}$ from the station, the algorithm sums the effects of four sloping triangular sections, measured around the station (the surface between the station and the elevation at each diagonal corner of the pixel of produced DTM was used). The calculation was done using Eq. (4) (Nagy, 1966):

$g=G \rho \varphi\left(R-\sqrt{R^{2}+H^{2}}+\frac{H^{2}}{\sqrt{R^{2}+H^{2}}}\right)$,

where $g$ is the gravitational attraction, $\rho$ the terrain density (here 2.67 $\left.\mathrm{g} / \mathrm{cm}^{3}\right), \varphi$ the horizontal angle of the triangular section, $G$ the gravitational constant, $H$ the difference between the station elevation and the average elevation of the diagonal corner, and $R$ the specific distance (here $5 \mathrm{~m})$.

In the intermediate zone ( 5 to $40 \mathrm{~m}$ ), the terrain effect is calculated for each point using the flat-topped square prism approach of Nagy (1966) (Eq. (6)). The terrain height is measured on a regular grid (equal spacing) with a total of $N \times M$ points. Then the terrain correction can be computed by summing up these $N \times M$ prisms using Eq. (5):

$g=\left.\left.\left.G \rho\right|_{z_{1}} ^{z_{2}}\right|_{y_{1}} ^{y_{2}}\right|_{x_{1}} ^{x_{2}} x \ln (y+r)+y \ln (x+r)-z \sin ^{-1}\left(\frac{z^{2}+y^{2}+y r}{(y+r) \sqrt{y^{2}+z^{2}}}\right)|| \mid,(5)$

where $g$ is the vertical component of the attraction, $\rho$ the density (here $\left.2.67 \mathrm{~g} / \mathrm{cm}^{3}\right), G$ the gravitational constant, and $r$ the distance between a unit mass and the station.

In the far zone ( $40 \mathrm{~m}$ to $200 \mathrm{~km}$ ), the terrain effect is derived based on the approximation of an annular ring segment to a square prism, as described by Kane (1962). The gravitational attraction is calculated by Eq. (6) (Kane, 1962):

$g=2 G \rho A^{2} \frac{\left(R_{2}-R_{1} \sqrt{R_{1}^{2}+H^{2}}-\sqrt{R_{2}^{2}+H^{2}}\right)}{\left(R_{2}^{2}-R_{1}^{2}\right)}$, 
where $g$ is the gravitational attraction, $\rho$ the terrain density (here 2.67

$\left.\mathrm{g} / \mathrm{cm}^{3}\right), A$ the length of the horizontal side of the prism, $R_{1}$ the radius of the inner circle of the annular ring, $R_{2}$ the radius of the outer circle of the annular ring, and $H$ the height of the annular ring or prism (we neglect the error at calculations using Eq. (6) from the Earth curvature because it is under standard error of our measurements).

\section{H. Gravity anomalies}

According to the above reduction schema, gravity anomalies can be calculated by the equations:

$F A A=G a b s-G \bmod -\delta g F A$,

$S B G=F A A-\delta g B C$,

$C B G=S B G+T C$,

$F A A$ stands for free air anomaly, $S B G$ represents simple Bouguer gravity anomaly and $C B G$ is complete Bouguer gravity anomaly.

\section{Interpolation}

To generate gravity anomaly maps for geological interpretation, gravity anomalies need to be expressed on a regular grid. However, gravity measurements are not homogeneously distributed. According to Eckstein (1989), due to the fact that the effectiveness of a particular interpolation method depends on the distribution of the observations and field gradients, no gridding algorithm should be considered "perfect". Nevertheless, some interpolation approaches are more suitable than others. Using a "trial and error" approach, Empirical Bayesian Kriging was selected, which creates a spectrum of semi-variograms, contrary to other Kriging methods that assume that the estimated semi-variogram is the true one for the observed data.

The selected gridding method minimizes the standard prediction error of the actual data as well as the difference in predicted and measured values at 10 carefully selected independent benchmark studies, which were not used in the interpolation. Parameters for the selected interpolation method are presented in Table 2. 
Table 2. Parameters and statistics of the selected interpolation method.

\begin{tabular}{|c|c|c|c|c|c|c|c|c|}
\hline $\begin{array}{c}\text { Gridding } \\
\text { method }\end{array}$ & $\begin{array}{c}\text { Subset } \\
\text { size } \\
\text { (values) }\end{array}$ & $\begin{array}{c}\text { Semi- } \\
\text { variogram } \\
\text { type }\end{array}$ & $\begin{array}{c}\text { Neigh- } \\
\text { bourhood } \\
\text { type }\end{array}$ & $\begin{array}{c}\text { Neigh- } \\
\text { bours } \\
\text { (values) }\end{array}$ & $\begin{array}{c}\text { Radius } \\
\begin{array}{c}\text { 岕 } \\
\text { (metres) }\end{array}\end{array}$ & $\begin{array}{c}\text { Average } \\
\text { standard } \\
\text { error } \\
\text { (mGal) }\end{array}$ & $\begin{array}{c}\text { Max error } \\
\text { in } \\
\text { independent } \\
\text { measure- } \\
\text { ments } \\
\text { (mGal) }\end{array}$ \\
\hline $\begin{array}{c}\text { Empirical } \\
\text { Bayesian } \\
\text { kriging }\end{array}$ & 60 & Power & $\begin{array}{c}\text { Standard } \\
\text { circular }\end{array}$ & 10 & 4 & 2500 & 2.1154 & 0.448 \\
\hline
\end{tabular}

\section{Results}

\section{A. Maps and statistics}

To achieve sufficient coverage, it was necessary to adjust the 1969, 1976, and HMGS gravity datasets together to produce the "older" gravity map. Additionally, the 2012 and 2014 datasets were adjusted together to produce the newer gravity map. To add offshore coverage, the latter two datasets were combined with the marine gravity survey of 2015 .

Figures 2 and 3 and Table 3 show the final results for the two datasets. Results of both datasets are very similar; small differences are due to the distribution of measurements. Regional maxima, present in both datasets, are found at Athinios, Fira and Profitis Ilias, where the geologic formations seem to be more dense, as they represent pre-volcanic units (Druitt, 2014). Regional minima, also present in both datasets, were observed southwest of Oia and Akrotiri Village and coincide with the Kolumbo fault zones and Akrotiri earlier geological formations (Druitt, 2014), respectively (Fig. 4).

Table 3. Statistics of free air and complete Bouguer gravity anomalies for each dataset.

\begin{tabular}{|c|cccc|}
\hline & FAA_70s & FAA_2014 & CBG_70s & CBG_2014 \\
\hline min & 70.552 & 70.432 & 98.38 & 97.724 \\
$\max$ & 169.203 & 171.652 & 143.144 & 143.113 \\
mean & 104.46 & 104.558 & 120.357 & 120.446 \\
stdv & 16.307 & 16.532 & 9.008 & 8.996 \\
\hline
\end{tabular}




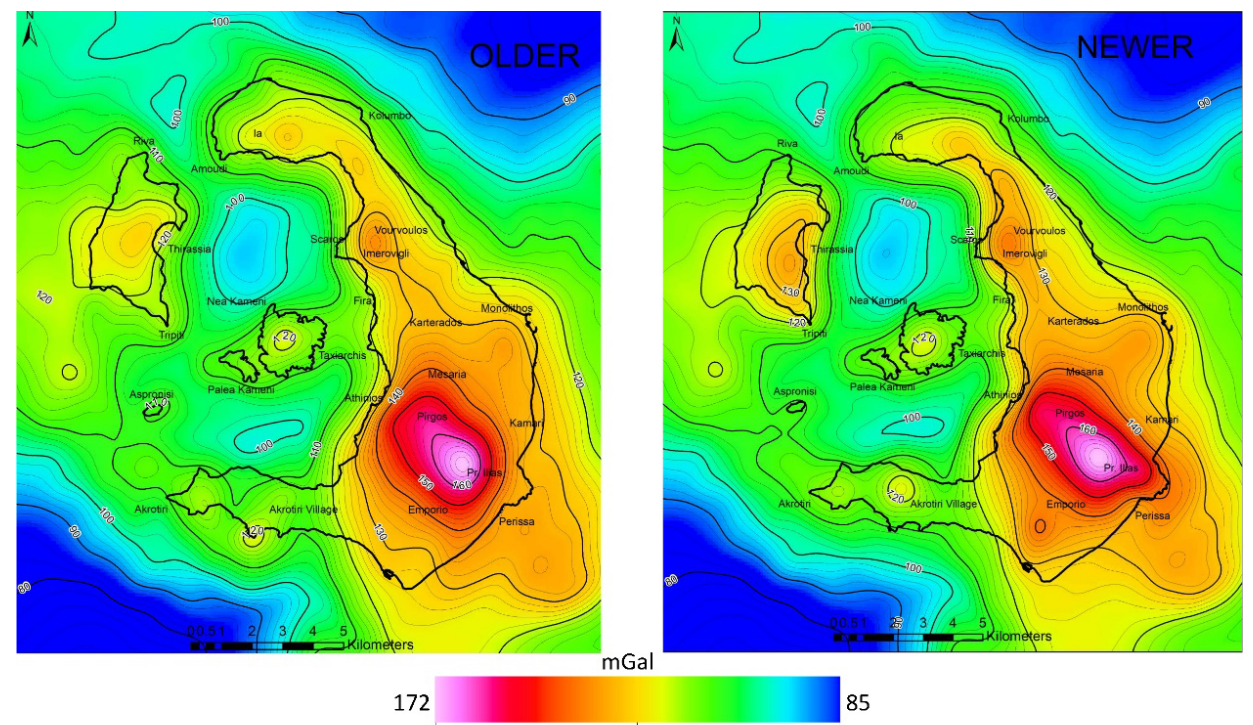

Fig. 2. Free air gravity anomalies in the area of Santorini, (a) using gravity measurements from 1966 to 1976, (b) using the datasets of 2012 and 2014. Contour interval is $2 \mathrm{mGal}$. Empirical Bayesian kriging was used for interpolation.

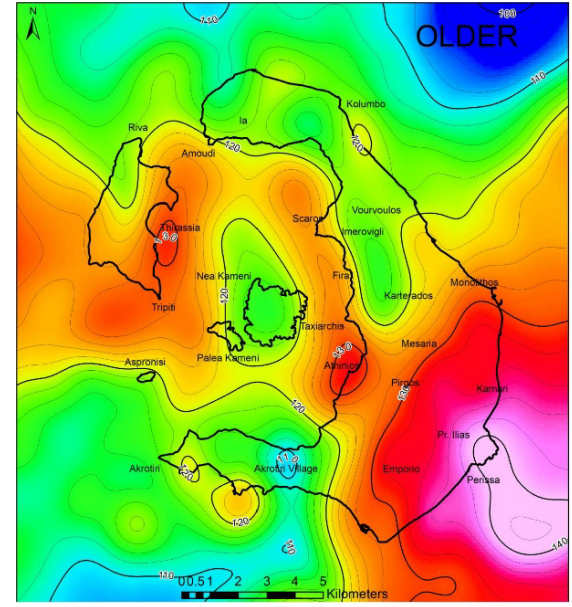

140

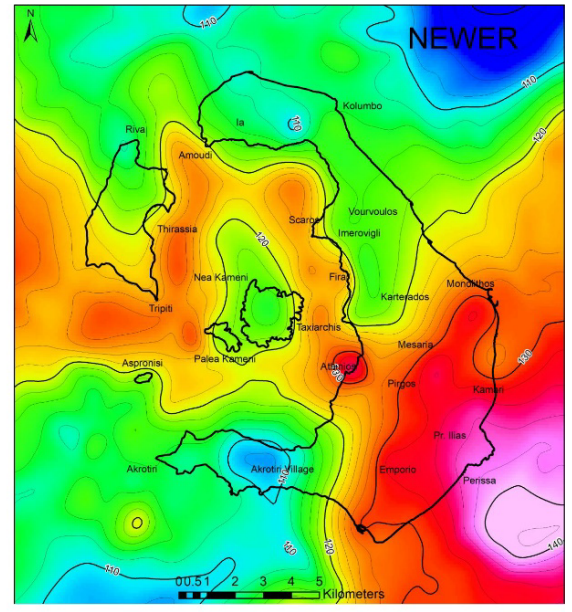

105

Fig. 3. Complete Bouguer gravity anomalies at the area of Santorini (a) using gravity values from 1966 to 1976, (b) using the datasets of 2012 and 2014. Contour interval is 2 mGal. Empirical Bayesian kriging was used for interpolation. 


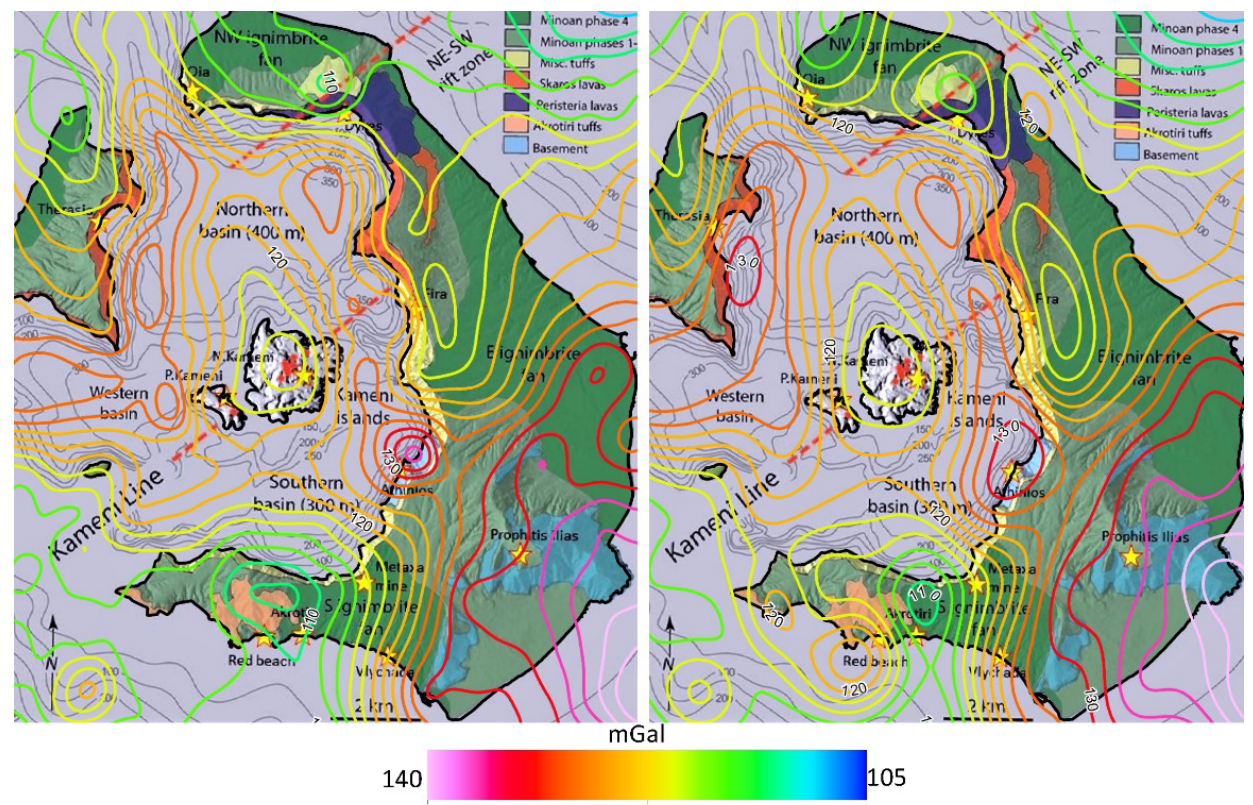

Fig. 4. Complete Bouguer gravity anomalies at the area of Santorini over simplified geologic map of the Santorini volcanic complex (Druitt, 2014), (a) using the datasets of 2012 and 2014, (b) using gravity values from 1966 to 1976. Contour interval is $2 \mathrm{mGal}$.

\section{B. Analysis}

The Complete Bouguer Gravity Anomaly maps for both datasets reveal a nearly elliptical zone at the centre of the caldera that includes the islands of Palea and Nea Kameni and the calculated Mogi-point inflation source for the 2011-2012 unrest period (e.g., Parks et al., 2012; Newman et al., 2012). These results are also consistent with the P-wave seismic velocity structure of Santorini that reveals a low-velocity anomaly in the upper $3 \mathrm{~km}$, with a diameter of $3 \pm 0.5 \mathrm{~km}$, which is confined beneath the north-central portion of the caldera (Hooft et al., 2019).

A quantitative analysis for temporal gravity changes was performed by comparing values at exactly the same point for both datasets (Fig. 5). Table 4 shows that there are significant differences in absolute gravity values around the centre of the caldera. In contrast, for the rest of the island the differences are near the standard deviation of each station. This implies that 
the inner processes of the volcano are still active. More detailed analysis will be the main objective of another paper.

Table 4. Gravity variation with time at same benchmarks measured at different epochs.

\begin{tabular}{|c|rrrrrrr|}
\hline station & latitude & longitude & elevation & dyear & dg & SDV & annual dg \\
\hline units & $\begin{array}{c}\text { dec } \\
\text { degrees }\end{array}$ & $\begin{array}{c}\text { dec } \\
\text { degrees }\end{array}$ & metres & & mGal & mGal & $\mu$ Gal/year \\
\hline $\begin{array}{c}\text { Nea Kameni } \\
\text { Port }\end{array}$ & 36.4110 & 25.4003 & 1.465 & $2014-1976$ & 0.256 & 0.031 & 6.74 \\
$\begin{array}{c}\text { Nea Kameni } \\
\text { middle }\end{array}$ & 36.4104 & 25.4012 & 2.010 & $2014-1975$ & 0.246 & 0.042 & 6.30 \\
$\begin{array}{c}\text { Centre of } \\
\text { Nea Kameni }\end{array}$ & 36.4045 & 25.3949 & 126.737 & $2012-1976$ & 0.385 & 0.027 & 10.70 \\
$\begin{array}{c}\text { Taxiarchis } \\
\text { N. Kameni) }\end{array}$ & 36.4004 & 25.4049 & 2.962 & $2012-1976$ & 0.290 & 0.025 & 8.06 \\
$\begin{array}{c}\text { Palea } \\
\text { Kameni }\end{array}$ & 36.3990 & 25.3805 & 1.021 & $2012-1976$ & 0.277 & 0.027 & 7.69 \\
Athinios & 36.3868 & 25.4308 & 1.596 & $2014-1976$ & 0.076 & 0.015 & 2.01 \\
Aspronisi & 36.3825 & 25.3490 & 3.200 & $2012-1976$ & 0.020 & 0.068 & 0.54 \\
$\begin{array}{c}\text { base } \\
\text { Emporeio Sq }\end{array}$ & 36.4073 & 25.4786 & 34.610 & $2012-2004$ & 0.015 & 0.009 & 1.84 \\
Vourvoulos & 36.3571 & 25.4447 & 76.548 & $2014-1976$ & -0.014 & 0.037 & -0.36 \\
$\begin{array}{c}\text { Perissa } \\
\text { South West }\end{array}$ & 36.4346 & 25.4362 & 123.537 & $2014-1976$ & 0.008 & 0.026 & 0.20 \\
of Oia & 36.3566 & 25.4744 & 4.400 & $2012-1975$ & 0.037 & 0.025 & 1.01 \\
$\begin{array}{c}\text { Fira } \\
\text { airport }\end{array}$ & 36.4183 & 25.4277 & 1.140 & $2014-1968$ & 0.062 & 0.024 & 1.34 \\
$\begin{array}{c}\text { Church } \\
\text { Athinios }\end{array}$ & 36.4031 & 25.4727 & 52.100 & $2014-2012$ & -0.006 & 0.014 & -2.85 \\
lighthouse & 36.3862 & 25.4381 & 299.101 & $2014-2012$ & 0.007 & 0.019 & 3.65 \\
\hline
\end{tabular}

\section{Conclusions}

To probe the internal structure of Santorini volcano and to determine whether there are temporal variations in gravity due to near surface changes, we construct two gravity maps. We carefully applied data correction and gridding to several historic gravity datasets to produce two gravity anomaly maps that correspond to the years before and after the 2011-2012 volcanic unrest episode at the volcano (the 1970s and 2012-2014, respectively). Through a comparative study, there are not significant qualitative differ- 


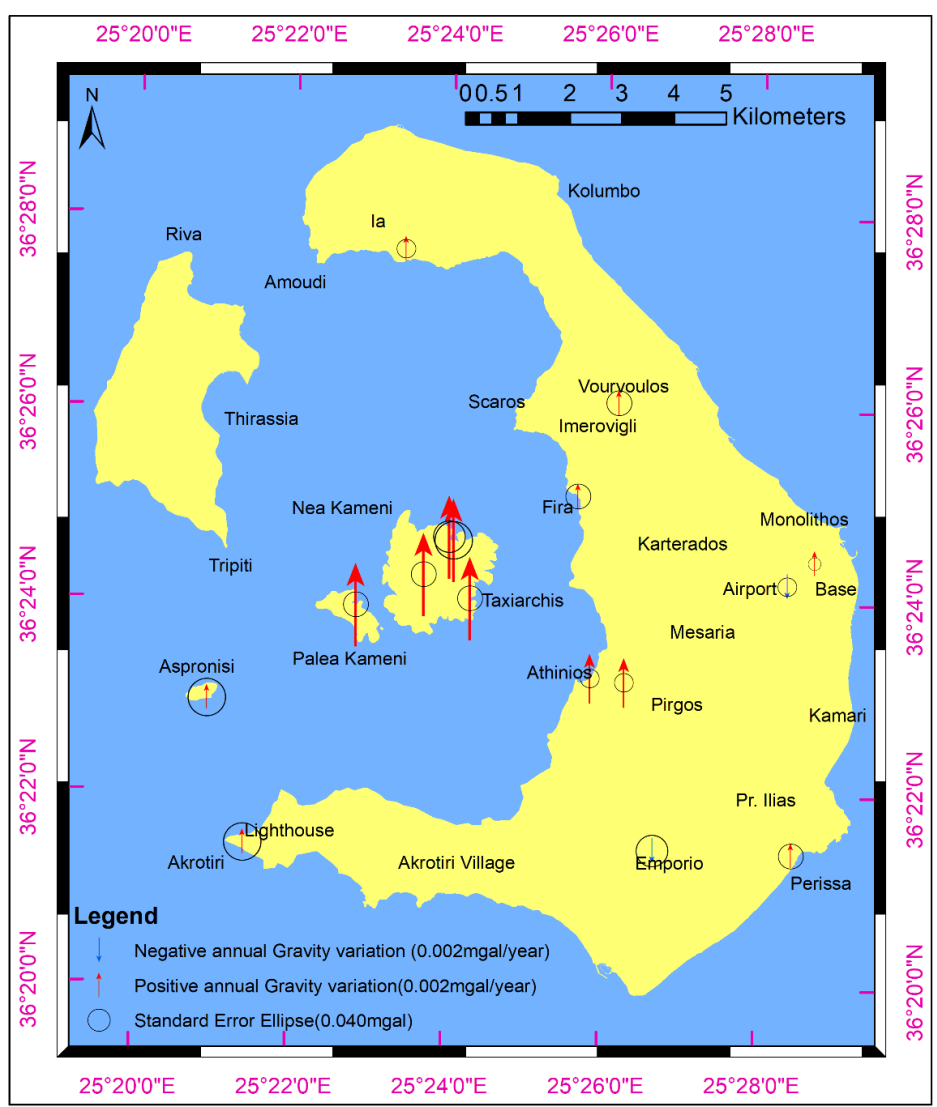

Fig. 5. Annual gravity variation with time at same benchmarks measured at different epochs.

ences between the two maps. An almost elliptical gravity minimum near the centre of the caldera is in good agreement with the seismic low velocity structure of Hooft et al. (2019). Regional maxima were observed in both maps at Athinios, Fira and Pr. Ilias, where the rock units are more dense. Regional minima in both datasets are located southwest of Oia and at Akrotiri Village, coinciding with the Kolumbo and Akrotiri fault zones, respectively. Significant differences in the complete Bouguer gravity anomalies between the two maps were only found within the caldera, indicating temporal changes in density of the upper crust that suggest that the inner process of the volcano is still active. 
Acknowledgements. The authors are indebted to the Hellenic Military Geographical Service for the data and instrumentation that they provided. The marine gravity data collection was supported by the US National Science Foundation under grant number OCE-1459794 to the University of Oregon.

\section{References}

Agatza-Balodimou A. M., Papazissi K., 1984: The gravity field of Santorini, Techn. Chron. - A, Greece, 4, 4, 5-17 (in Greek with with English summary).

Battaglia M., Gottsmann J., Carbone D., Fernández J., 2008: 4D volcano gravimetry. Geophysics, 73, 6, WA3-WA18, doi: 10.1190/1.2977792.

Bureau Gravimétrique International (BGI): Gravity measurements published at http:// bgi.obs-mip.fr, doi: 10.18168/BGI.

Druitt T. H., 2014: New insights into the initiation and venting of the Bronze-Age eruption of Santorini (Greece), from component analysis. Bull. Volcanol., 76, 794, doi: 10.1007/s00445-014-0794-x.

Eckstein B. A., 1989: Evaluation of spline and weighted average interpolation algorithms. Comput. Geosci., 15, 1, 79-94, doi: 10.1016/0098-3004 (89)90056-3.

Förste Ch., Bruinsma S. L., Abrikosov O., Lemoine J.-M., Schaller T., Götze H.-J., Ebbing J., Marty J. C., Flechtner F., Balmino G., Biancale R., 2014: EIGEN6C4 - The latest combined global gravity field model including GOCE data up to degree and order 2190 of GFZ Potsdam and GRGS Toulouse. In: Proceedings of 5th International GOCE User Workshop, Paris 25 - 28 Nov. 2014.

Hildenbrand T. G., Briesacher A., Flanagan G., Hinze W. J., Hittelman A. M., Keller G. R., Kucks R. P., Plouff D., Roest W., Seeley J., Smith D. A., Webring M., 2002: Rationale and operational plan to upgrade the U.S. gravity database. U.S. Geological Survey Open-File Report, 2002-463, 12 p., doi: 10.3133/ofr02463.

Hofmann-Wellenhof B., Moritz H., 2005: Physical Geodesy. Springer-Verlag Wien, 403 p., doi: $10.1007 / \mathrm{b} 139113$.

Hooft E. E. E., Toomey D. Nomikou P., 2015: PROTEUS: Plumbing reservoirs of the Earth under Santorini. MGL1521 Cruise report 2015, website: https://pages .uore gon.edu/emilie/PROTEUS/.

Hooft E. E. E., Heath B. A., Toomey D. R., Paulatto M., Papazachos C. B., Nomikou P., Morgan J. V., Warner M. R., 2019: Seismic imaging of Santorini: Subsurface constraints on caldera collapse and present-day magma recharge. Earth Planet. Sci. Lett., 514, 48-61, doi: 10.1016/j.epsl.2019.02.033.

Hsu S.-K., 1995: XCORR: A cross-over technique to adjust track data. Comput. Geosci., 21, 2, 259-271, doi: 10.1016/0098-3004(94)00070-B.

Kane M. F., 1962: A comprehensive system of terrain corrections using a digital computer. Geophysics, 27, 4, 455-462, doi: 10.1190/1.1439044.

LaFehr T. R., 1991: An exact solution for the gravity curvature (Bullard B) correction. Geophysics, 56, 8, 1179-1184, doi: 10.1190/1.1443138.

Lyard F., Lefevre F., Letellier T., Francis O., 2006: Modelling the global ocean tides: modern insights from FES2004. Ocean Dyn., 56, 5-6, 394-415, doi : 10.1007/s10236-00 


$$
\text { 6-0086-x. }
$$

Longman I. M., 1959: Formulas for computing the tidal accelerations due to the moon and the sun. J. Geophys. Res., 64, 12, 2351-2355, doi : 10.1029/JZ064i012p02351.

Nagy D., 1966: The gravitational attraction of a right rectangular prism. Geophysics, 31, 2, 362-371, doi: 10.1190/1.1439779.

NASA and METI, 2011: ASTER Global Digital Elevation Model (GDEM) v2 data is a product of NASA and METI, released at October 17, 2011, pixel size 30 meters.

Newman A. V., Stiros S., Feng L., Psimoulis P., Moschas F., Saltogianni V., Jiang Y., Papazachos C., Panagiotopoulos G., Karagianni E., Vamvakaris D., 2012: Recent geodetic unrest at Santorini Caldera, Greece. Geophys. Res. Lett., 39, 6, L06309, doi : 10.1029/2012GL051286.

Nomikou P., Parks M. M., Papanikolaou D., Pyle D. M., Mather T. A., Carey S., Watts A. B., Paulatto M., Kalnins M. L., Livanos I., Bejelou K., Simou E., Perros I., 2014: The emergence and growth of a submarine volcano: The Kameni islands, Santorini (Greece). GeoResJ, 1-2, 8-18, doi: 10.1016/j.grj.2014.02.002.

Papadopoulos N., Paraskevas M., Katsafados I., Nikolaidis G., 2019: Calculating a geoid model for Greece using gravity and GPS observations. Conference JISDM 2019, May 2019, doi: 10.13140/RG.2.2.22623.71841/1.

Papanikolaou T. D., 2012: Dynamic modelling of satellite orbits in the frame of contemporary satellite geodesy missions. Ph.D. Dissertation, Aristotle University of Thessaloniki, Greece (in Greek).

Papanikolaou T. D., 2013: Development of GRAVsynth software for spherical harmonic synthesis. User guide, Department of Gravimetry, Hellenic Military Geographical Service, Athens, Greece (in Greek).

Paraskevas M., Paradissis D., Kolovos I., Nomikou P., Papanikolaou D., Raptakis C., 2014: Tectonic structure of Santorini volcanic field based on terrestrial gravity measurements (1976-2012). In: 1st International Geo-Cultural Symposium Kaldera, 6-8 June 2014, Santorini, Greece, http://www .mesonisos.gr/images/ABSTRACT_VOLUME .pdf.

Paraskevas M., Paradissis D., Raptakis C., Nomikou P., Hooft E. E., Papanikolaou D., 2019: Geodetic and geophysical approach of the gravitational field in Santorini Volcanic Group, Conference JISDM 2019, Athens, Greece, May 2019, doi: 10.13140/RG.2.2.15196.03209.

Parks M. M., Biggs J., England P., Mather T. A., Nomikou P., Palamartchouk K., Papanikolaou X., Paradissis D., Parsons B., Pyle D. M., Raptakis C., Zacharis V., 2012: Evolution of Santorini Volcano dominated by episodic and rapid fluxes of melt from depth. Nat. Geosci., 5, 749-754, doi: 10.1038/ngeo1562.

Pavlis N. K., Holmes S. A., Kenyon S. C., Factor J. K., 2012: The development and evaluation of the Earth Gravitational Model 2008 (EGM2008). J. Geophys. Res., 117, B4, B04406, doi: 10.1029/2011JB008916.

Petit G., Luzum B., 2010: IERS Conventions (2010), IERS Technical Note No. 36. Verlag des Bundesamts für Kartographie und Geodäsie, Frankfurt am Main.

Seigel H. O., 1995: A guide to high precision land gravimeter surveys. Scintrex Limited, Canada, 132 p. 
Somigliana C., 1930: Sul campo gravitazionale esterno del geoide ellissoidico. Atti della Accademia nazionale dei Lincei Rendiconti, Classe di scienze fisiche, matematiche e naturali. Geofisica, 237-243.

Torge W., 1989: Gravimetry. de Gruyter, Berlin-New York 1989, p. 327-328.

Vajda P., 2016: Recent Developments and Trends in Volcano Gravimetry. In: Nemeth K. (Ed.): Updates in Volcanology: From Volcano Modelling to Volcano Geology, doi: $10.5772 / 63420$.

Williams-Jones G., Rymer H., Mauri G., Gottsmann J., Poland M., Carbone D., 2008: Towards continuous 4D microgravity monitoring of volcanoes. Geophysics, 73, 6, WA19-WA28, doi : 10.1190/1.2981185.

Yokoyama I., Bonasia V., 1978: Gravity anomalies on the Thera Islands. In: Doumas C. (Ed.): Thera and the Aegean World I. The Thera Foundation, London, 147-150.

Yu H., Guo J., Kong Q., Chen X., 2019: Gravity Tides Extracted from Relative Gravimeter Data by Combining Empirical Mode Decomposition and Independent Component Analysis. In: Braitenberg C., Rossi G., Geodynamics and Earth Tides Editor group (Eds.): Geodynamics and Earth Tides Observations from Global to Micro Scale. Pageoph Topical Volumes. Birkhäuser, Cham, pp. 89-103, doi : 10.1007/978 -3-319-96277-1_9.

\section{Appendix 1}

Gravity campaign of 1976

\begin{tabular}{|c|lcccccc|}
\hline Station & latitude & longitude & elevation & Gpotsdam & SDV & G(WGS84) & FAA \\
\hline units & degrees & degrees & meter & mGal & mGal & mGal & mGal \\
\hline 2 & 36.3868 & 25.4308 & 1.596 & 979993.359 & 0.012 & 979979.349 & 127.32 \\
3 & 36.3712 & 25.4823 & 5 & 979997.488 & 0.016 & 979983.477 & 133.843 \\
4 & 36.3493 & 25.4 & 1 & 979971.133 & 0.016 & 979957.123 & 108.151 \\
5 & 36.3496 & 25.4036 & 30 & 979966.828 & 0.016 & 979952.815 & 112.764 \\
6 & 36.3596 & 25.4038 & 72.57 & 979953.732 & 0.018 & 979939.714 & 111.94 \\
7 & 36.3666 & 25.4269 & 139.1 & 979953.863 & 0.019 & 979939.839 & 131.985 \\
8 & 36.3571 & 25.4447 & 76.548 & 979979.705 & 0.028 & 979965.688 & 139.353 \\
9 & 36.3564 & 25.4754 & 3.86 & 979997.139 & 0.019 & 979983.129 & 134.421 \\
10 & 36.3437 & 25.4519 & 12.83 & 979988.615 & 0.017 & 979974.603 & 129.766 \\
11 & 36.3863 & 25.4634 & 64.35 & 979981.414 & 0.015 & 979967.397 & 134.778 \\
12 & 36.4006 & 25.4577 & 103 & 979969.792 & 0.017 & 979955.772 & 133.845 \\
13 & 36.4226 & 25.4344 & 179.35 & 979943.187 & 0.017 & 979929.159 & 128.891 \\
14 & 36.403 & 25.4373 & 190.18 & 979940.756 & 0.017 & 979926.727 & 131.5 \\
15 & 36.4092 & 25.4798 & 18.34 & 979992.777 & 0.015 & 979978.766 & 129.971 \\
16 & 36.4336 & 25.4273 & 296.45 & 979918.951 & 0.023 & 979904.912 & 139.832 \\
17 & 36.4572 & 25.4211 & 228.79 & 979932.442 & 0.029 & 979918.41 & 130.415 \\
18 & 36.4662 & 25.4028 & 185.99 & 979941.135 & 0.032 & 979927.106 & 125.122 \\
\hline
\end{tabular}


Paraskevas M. et al.: Gravity observations on Santorini island...

$(1-24)$

\begin{tabular}{|c|llcllll|}
\hline 19 & 36.4631 & 25.3828 & 121.8 & 979956.72 & 0.034 & 979942.698 & 121.177 \\
20 & 36.4583 & 25.371 & 0.5 & 979985.647 & 0.034 & 979971.637 & 113.098 \\
21 & 36.3688 & 25.4633 & 555.37 & 979865.998 & 0.034 & 979851.934 & 172.358 \\
22 & 36.375 & 25.4531 & 328.28 & 979926.256 & 0.032 & 979912.214 & 162.02 \\
23 & 36.3842 & 25.4465 & 303.96 & 979929.413 & 0.029 & 979915.374 & 156.881 \\
24 & 36.3826 & 25.4336 & 258 & 979934.813 & 0.023 & 979920.777 & 148.237 \\
25 & 36.4183 & 25.4277 & 0.7 & 979987.261 & 0.021 & 979973.251 & 118.225 \\
26 & 36.411 & 25.4003 & 1.465 & 979981.058 & 0.023 & 979967.048 & 112.892 \\
27 & 36.4045 & 25.3949 & 126.737 & 979952.283 & 0.024 & 979938.261 & 123.326 \\
28 & 36.4075 & 25.3974 & 73.5 & 979963.959 & 0.017 & 979949.941 & 118.315 \\
29 & 36.4118 & 25.3885 & 0 & 979978.203 & 0.016 & 979964.193 & 109.515 \\
30 & 36.399 & 25.3805 & 1.021 & 979982.381 & 0.023 & 979968.371 & 115.108 \\
31 & 36.4004 & 25.4049 & 2.962 & 979980.852 & 0.021 & 979966.841 & 114.06 \\
32 & 36.3393 & 25.4324 & 9.24 & 979988.364 & 0.018 & 979974.353 & 128.786 \\
33 & 36.4346 & 25.4362 & 123.537 & 979959.559 & 0.019 & 979945.537 & 127.011 \\
34 & 36.4275 & 25.4599 & 3.27 & 979987.568 & 0.018 & 979973.558 & 118.527 \\
35 & 36.4101 & 25.4462 & 137.21 & 979956.683 & 0.017 & 979942.659 & 130.472 \\
36 & 36.3835 & 25.4787 & 26.85 & 979990.534 & 0.019 & 979976.521 & 132.569 \\
37 & 36.3661 & 25.3659 & 1.3 & 979976.851 & 0.054 & 979962.841 & 112.509 \\
38 & 36.3825 & 25.3497 & 0.1 & 979977.907 & 0.067 & 979963.897 & 111.775 \\
39 & 36.4089 & 25.3526 & 2 & 979987.467 & 0.071 & 979973.456 & 119.644 \\
40 & 36.4386 & 25.3513 & 1 & 979991.052 & 0.067 & 979977.041 & 120.353 \\
41 & 36.4338 & 25.3443 & 160 & 979950.488 & 0.054 & 979936.462 & 129.255 \\
\hline mean & 36.3982 & 25.4201 & 96.194 & 979965.341 & 0.026 & 979951.321 & 127.5 \\
max & 36.4662 & 25.4823 & 555.37 & 979997.488 & 0.071 & 979983.477 & 172.358 \\
min & 36.3393 & 25.3443 & 0 & 979865.998 & 0.012 & 979851.934 & 108.151 \\
SDV & 0.0342 & 0.0387 & 123.171 & 27.249 & 0.015 & 27.26 & 14.214 \\
\hline
\end{tabular}

\section{Appendix 2}

Gravity campaign of 2012

\begin{tabular}{|c|lcccccc|}
\hline Station & latitude & longitude & elevation & Gpotsdam & SDV & G(WGS84) & FAA \\
\hline units & degrees & degrees & meter & mGal & mGal & mGal & mGal \\
\hline 1001 & 36.4031 & 25.4727 & 52.1 & 979987.902 & 0.011 & 979973.887 & 136.032 \\
1002 & 36.4328 & 25.4224 & 360.07 & 979898.859 & 0.012 & 979884.814 & 139.44 \\
1003 & 36.4619 & 25.3832 & 137.3 & 979952.422 & 0.012 & 979938.398 & 121.765 \\
1004 & 36.458 & 25.3399 & 16.5 & 979979.231 & 0.035 & 979965.219 & 111.639 \\
1005 & 36.442 & 25.3534 & 226.684 & 979930.486 & 0.037 & 979916.453 & 129.118 \\
1006 & 36.4266 & 25.3467 & 294.979 & 979914.782 & 0.035 & 979900.743 & 135.815 \\
1007 & 36.4128 & 25.3507 & 196.278 & 979935.385 & 0.034 & 979921.356 & 127.161 \\
1008 & 36.43 & 25.3249 & 16.8 & 979987.517 & 0.029 & 979973.505 & 122.436 \\
1009 & 36.4529 & 25.4237 & 316.775 & 979908.113 & 0.013 & 979894.072 & 133.603 \\
\hline
\end{tabular}




\begin{tabular}{|c|c|c|c|c|c|c|c|}
\hline 1010 & 36.4608 & 25.3899 & 156.3 & 979947.616 & 0.014 & 979933.591 & 122.911 \\
\hline 1011 & 36.4804 & 25.3824 & 7.9 & 979982.332 & 0.029 & 979968.321 & 110.15 \\
\hline 1012 & 36.4728 & 25.4213 & 47.43 & 979974.742 & 0.017 & 979960.727 & 115.415 \\
\hline 1013 & 36.4684 & 25.4242 & 6.53 & 979984.834 & 0.016 & 979970.824 & 113.266 \\
\hline 1014 & 36.4634 & 25.4057 & 330.516 & 979901.835 & 0.015 & 979887.792 & 130.65 \\
\hline 1015 & 36.4447 & 25.4436 & 59.508 & 979974.488 & 0.014 & 979960.472 & 121.314 \\
\hline 1016 & 36.4338 & 25.448 & 77.183 & 979971.232 & 0.013 & 979957.214 & 124.452 \\
\hline 1017 & 36.4045 & 25.3949 & 126.737 & 979952.669 & 0.013 & 979938.646 & 123.711 \\
\hline 1018 & 36.4063 & 25.3965 & 100.2 & 979958.062 & 0.013 & 979944.042 & 120.759 \\
\hline 1019 & 36.4084 & 25.3999 & 53.3 & 979970.412 & 0.014 & 979956.397 & 118.457 \\
\hline 1020 & 36.4085 & 25.4013 & 57.399 & 979968.914 & 0.014 & 979954.898 & 118.217 \\
\hline 1021 & 36.4102 & 25.3998 & 17.05 & 979977.126 & 0.014 & 979963.114 & 113.834 \\
\hline 1022 & 36.4004 & 25.4049 & 2.962 & 979981.142 & 0.014 & 979967.132 & 114.35 \\
\hline 1023 & 36.4042 & 25.4307 & 239.09 & 979925.667 & 0.014 & 979911.633 & 131.396 \\
\hline 1024 & 36.3874 & 25.4367 & 300.28 & 979924.446 & 0.014 & 979910.407 & 150.497 \\
\hline 1025 & 36.4136 & 25.4543 & 90.4 & 979969.938 & 0.014 & 979955.919 & 128.984 \\
\hline 1026 & 36.4199 & 25.471 & 19.8 & 979987.618 & 0.012 & 979973.606 & 124.333 \\
\hline 1027 & 36.4072 & 25.479 & 52.613 & 979986.584 & 0.013 & 979972.568 & 134.52 \\
\hline 1028 & 36.3916 & 25.4862 & 2.9 & 979991.431 & 0.013 & 979977.42 & 125.382 \\
\hline 1029 & 36.3836 & 25.4722 & 48.5 & 979985.844 & 0.013 & 979971.83 & 134.552 \\
\hline 1030 & 36.3812 & 25.4491 & 307.4 & 979930.227 & 0.013 & 979916.187 & 159.013 \\
\hline 1031 & 36.3688 & 25.4631 & 552.4 & 979866.396 & 0.014 & 979852.333 & 171.834 \\
\hline 1032 & 36.3704 & 25.4584 & 500.1 & 979880.593 & 0.031 & 979866.535 & 169.76 \\
\hline 1033 & 36.3862 & 25.4381 & 299.101 & 979928.231 & 0.012 & 979914.191 & 154.027 \\
\hline 1034 & 36.3827 & 25.4336 & 259.969 & 979934.026 & 0.012 & 979919.99 & 148.047 \\
\hline 1035 & 36.3826 & 25.3497 & 0.4 & 979978.069 & 0.013 & 979964.059 & 112.021 \\
\hline 1036 & 36.3823 & 25.3475 & 2.3 & 979978.411 & 0.013 & 979964.401 & 112.976 \\
\hline 1037 & 36.3822 & 25.3471 & 1.2 & 979978.216 & 0.013 & 979964.206 & 112.455 \\
\hline 1038 & 36.3825 & 25.349 & 3.2 & 979977.847 & 0.013 & 979963.836 & 112.671 \\
\hline 1039 & 36.3825 & 25.3497 & 0.1 & 979977.926 & 0.013 & 979963.916 & 111.795 \\
\hline 1040 & 36.3939 & 25.3855 & 4.055 & 979981.558 & 0.014 & 979967.548 & 115.669 \\
\hline 1041 & 36.3991 & 25.3804 & 2.529 & 979982.204 & 0.014 & 979968.194 & 115.393 \\
\hline 1042 & 36.399 & 25.3805 & 1.021 & 979982.628 & 0.014 & 979968.618 & 115.355 \\
\hline 1043 & 36.3969 & 25.3765 & 1.135 & 979980.803 & 0.013 & 979966.793 & 113.747 \\
\hline 1044 & 36.3324 & 25.4424 & 1.72 & 979987.804 & 0.013 & 979973.793 & 126.497 \\
\hline 1045 & 36.3566 & 25.4744 & 4.4 & 979997.352 & 0.013 & 979983.341 & 134.789 \\
\hline 1046 & 36.3471 & 25.4386 & 169.52 & 979953.511 & 0.014 & 979939.485 & 142.705 \\
\hline 1047 & 36.3576 & 25.3571 & 99.36 & 979950.637 & 0.014 & 979936.617 & 117.277 \\
\hline 1048 & 36.357 & 25.3592 & 134.822 & 979940.836 & 0.014 & 979926.813 & 118.469 \\
\hline 1049 & 36.3588 & 25.3892 & 210.06 & 979923.049 & 0.013 & 979909.019 & 123.735 \\
\hline 1050 & 36.3526 & 25.3996 & 91.8 & 979949.822 & 0.013 & 979935.803 & 114.564 \\
\hline 1051 & 36.3754 & 25.4256 & 198.99 & 979941.401 & 0.012 & 979927.371 & 137.24 \\
\hline 1052 & 36.3653 & 25.4769 & 365.574 & 979912.002 & 0.013 & 979897.956 & 160.107 \\
\hline 2000 & 36.4073 & 25.4786 & 34.61 & 979992.925 & 0.009 & 979978.912 & 135.305 \\
\hline
\end{tabular}


Paraskevas M. et al.: Gravity observations on Santorini island...

$(1-24)$

\begin{tabular}{|c|rrcrrrc|}
\hline mean & 36.4036 & 25.4096 & 125.658 & 979956.945 & 0.016 & 979942.923 & 127.728 \\
$\max$ & 36.4804 & 25.4862 & 552.4 & 979997.352 & 0.037 & 979983.341 & 171.834 \\
$\min$ & 36.3324 & 25.3249 & 0.1 & 979866.396 & 0.009 & 979852.333 & 110.15 \\
SDV & 0.0355 & 0.0451 & 140.185 & 31.721 & 0.007 & 31.734 & 15.264 \\
\hline
\end{tabular}

\section{Appendix 3}

Gravity campaign of 2014

\begin{tabular}{|c|c|c|c|c|c|c|c|}
\hline Station & latitude & longitude & elevation & Gpotsdam & SDV & G(WGS84) & FAA \\
\hline units & degrees & degrees & meter & $\mathrm{mGal}$ & $\mathrm{mGal}$ & $\mathrm{mGal}$ & $\mathrm{mGal}$ \\
\hline 1001 & 36.4031 & 25.4727 & 52.1 & 979987.896 & 0.013 & 979973.881 & 136.026 \\
\hline 1017 & 36.4045 & 25.3949 & 126.737 & 979952.693 & 0.015 & 979938.67 & 123.735 \\
\hline 1020 & 36.4085 & 25.4013 & 57.399 & 979968.923 & 0.027 & 979954.907 & 118.226 \\
\hline 1033 & 36.3862 & 25.4381 & 299.101 & 979928.238 & 0.015 & 979914.199 & 154.035 \\
\hline 1034 & 36.3827 & 25.4336 & 259.969 & 979934.009 & 0.014 & 979919.974 & 148.031 \\
\hline 1047 & 36.3576 & 25.3571 & 99.269 & 979950.664 & 0.013 & 979936.644 & 117.276 \\
\hline 1100 & 36.3868 & 25.4308 & 1.596 & 979993.43 & 0.009 & 979979.42 & 127.392 \\
\hline 1101 & 36.3751 & 25.48 & 22.701 & 979994.1 & 0.013 & 979980.087 & 135.584 \\
\hline 1102 & 36.4119 & 25.4373 & 181.272 & 979945.138 & 0.016 & 979931.111 & 132.366 \\
\hline 1103 & 36.4201 & 25.4306 & 237.125 & 979929.31 & 0.017 & 979915.277 & 133.056 \\
\hline 1104 & 36.4183 & 25.4277 & 1.14 & 979987.004 & 0.019 & 979972.994 & 118.104 \\
\hline 1105 & 36.4104 & 25.4012 & 2.01 & 979981.549 & 0.022 & 979967.539 & 113.597 \\
\hline 1106 & 36.4092 & 25.4009 & 59.357 & 979968.223 & 0.023 & 979954.207 & 118.07 \\
\hline 1107 & 36.4075 & 25.3979 & 72.146 & 979964.612 & 0.023 & 979950.595 & 118.551 \\
\hline 1108 & 36.4053 & 25.3958 & 120.925 & 979953.385 & 0.026 & 979939.363 & 122.564 \\
\hline 1109 & 36.4042 & 25.3966 & 120.958 & 979953.887 & 0.026 & 979939.866 & 123.167 \\
\hline 1110 & 36.4056 & 25.3956 & 124.87 & 979951.893 & 0.027 & 979937.87 & 122.262 \\
\hline 1111 & 36.411 & 25.4003 & 1.465 & 979981.315 & 0.026 & 979967.305 & 113.149 \\
\hline 1112 & 36.4104 & 25.4015 & 2.471 & 979981.843 & 0.027 & 979967.833 & 114.038 \\
\hline 1113 & 36.3556 & 25.446 & 68.104 & 979980.36 & 0.016 & 979966.343 & 137.533 \\
\hline 1114 & 36.4599 & 25.4167 & 189.085 & 979942.344 & 0.017 & 979928.315 & 127.83 \\
\hline 1115 & 36.4603 & 25.4165 & 192.386 & 979941.121 & 0.019 & 979927.092 & 127.589 \\
\hline 1116 & 36.4619 & 25.4142 & 180.935 & 979944.352 & 0.019 & 979930.324 & 127.154 \\
\hline 1117 & 36.4627 & 25.4131 & 218.668 & 979934.477 & 0.019 & 979920.445 & 128.848 \\
\hline 1118 & 36.4613 & 25.416 & 185.52 & 979944.13 & 0.017 & 979930.102 & 128.396 \\
\hline 1119 & 36.4665 & 25.3684 & 3.837 & 979983.961 & 0.018 & 979969.951 & 111.731 \\
\hline 1120 & 36.4624 & 25.3697 & 26.698 & 979978.365 & 0.019 & 979964.352 & 113.541 \\
\hline 1121 & 36.4752 & 25.3828 & 30.285 & 979978.569 & 0.021 & 979964.556 & 113.746 \\
\hline 1122 & 36.4768 & 25.4076 & 15.726 & 979982.373 & 0.021 & 979968.361 & 112.917 \\
\hline 1123 & 36.4652 & 25.4211 & 37.457 & 979979.747 & 0.021 & 979965.734 & 117.997 \\
\hline 1124 & 36.4631 & 25.4243 & 33.074 & 979979.999 & 0.021 & 979965.986 & 117.085 \\
\hline 1125 & 36.4609 & 25.4208 & 122.078 & 979959.431 & 0.019 & 979945.409 & 124.164 \\
\hline
\end{tabular}




\begin{tabular}{|c|c|c|c|c|c|c|c|}
\hline 1126 & 36.4574 & 25.4195 & 214.354 & 979936.5 & 0.018 & 979922.469 & 130 \\
\hline 1127 & 36.4099 & 25.4417 & 168.536 & 979949.093 & 0.015 & 979935.066 & 132.564 \\
\hline 1128 & 36.3577 & 25.3561 & 78.012 & 979956.322 & 0.016 & 979942.304 & 116.367 \\
\hline 1129 & 36.3578 & 25.3553 & 54.4 & 979962.648 & 0.018 & 979948.632 & 115.405 \\
\hline 1130 & 36.3634 & 25.3855 & 158.838 & 979935.521 & 0.02 & 979921.496 & 120.01 \\
\hline 1131 & 36.3481 & 25.3876 & 2.842 & 979972.228 & 0.02 & 979958.218 & 109.914 \\
\hline 1132 & 36.3561 & 25.3817 & 121.471 & 979945.759 & 0.02 & 979931.737 & 119.349 \\
\hline 1133 & 36.3545 & 25.3761 & 4.195 & 979973.971 & 0.02 & 979959.961 & 111.524 \\
\hline 1134 & 36.3638 & 25.364 & 51.775 & 979963.809 & 0.018 & 979949.794 & 115.239 \\
\hline 1135 & 36.3581 & 25.3666 & 96.039 & 979953.643 & 0.016 & 979939.623 & 119.218 \\
\hline 1136 & 36.3372 & 25.4334 & 1.615 & 979990.62 & 0.015 & 979976.61 & 128.864 \\
\hline 1137 & 36.246 & 25.2094 & 9.684 & 979994.209 & 0.016 & 979980.198 & 142.814 \\
\hline 1138 & 36.2463 & 25.2092 & 28.758 & 979988.054 & 0.019 & 979974.041 & 142.513 \\
\hline 1139 & 36.2469 & 25.2084 & 34.67 & 979987.049 & 0.02 & 979973.035 & 143.286 \\
\hline 1140 & 36.2476 & 25.2083 & 44.553 & 979983.864 & 0.021 & 979969.85 & 143.083 \\
\hline 1141 & 36.2502 & 25.2076 & 50.131 & 979981.802 & 0.022 & 979967.787 & 142.518 \\
\hline 1142 & 36.251 & 25.2073 & 41.312 & 979983.324 & 0.021 & 979969.31 & 141.255 \\
\hline 1143 & 36.2454 & 25.2072 & 53.158 & 979980.966 & 0.02 & 979966.951 & 143.03 \\
\hline 1144 & 36.2446 & 25.2077 & 46.007 & 979982.301 & 0.019 & 979968.286 & 142.229 \\
\hline 1145 & 36.3835 & 25.4394 & 290.706 & 979931.228 & 0.015 & 979917.189 & 154.669 \\
\hline 1146 & 36.3801 & 25.4816 & 16.459 & 979994.036 & 0.016 & 979980.024 & 133.164 \\
\hline 1147 & 36.3874 & 25.4633 & 77.755 & 979983.622 & 0.016 & 979969.604 & 141.026 \\
\hline 1148 & 36.4007 & 25.4573 & 105.262 & 979969.393 & 0.018 & 979955.373 & 134.135 \\
\hline 1149 & 36.4015 & 25.4489 & 147.973 & 979956.833 & 0.02 & 979942.809 & 134.682 \\
\hline 1150 & 36.3935 & 25.4499 & 171.718 & 979957.03 & 0.021 & 979943.003 & 142.897 \\
\hline 1151 & 36.4098 & 25.4532 & 106.424 & 979966.491 & 0.022 & 979952.47 & 130.809 \\
\hline 1152 & 36.414 & 25.4445 & 135.254 & 979957.597 & 0.022 & 979943.574 & 130.441 \\
\hline 1153 & 36.4159 & 25.4365 & 180.771 & 979945.292 & 0.022 & 979931.265 & 132.02 \\
\hline 1154 & 36.4228 & 25.4392 & 150.228 & 979953.264 & 0.022 & 979939.24 & 129.973 \\
\hline 1155 & 36.4289 & 25.4586 & 18.216 & 979985.482 & 0.021 & 979971.47 & 120.937 \\
\hline 1156 & 36.4346 & 25.4362 & 123.537 & 979959.566 & 0.02 & 979945.544 & 127.019 \\
\hline 1157 & 36.4344 & 25.429 & 272.552 & 979925.636 & 0.018 & 979911.599 & 139.075 \\
\hline 1158 & 36.3851 & 25.4345 & 232.738 & 979946.111 & 0.016 & 979932.078 & 151.524 \\
\hline 1159 & 36.3866 & 25.4279 & 2.725 & 979992.235 & 0.019 & 979978.225 & 126.562 \\
\hline 1160 & 36.386 & 25.4284 & 2.311 & 979992.938 & 0.013 & 979978.928 & 127.192 \\
\hline 1161 & 36.3884 & 25.4319 & 3.322 & 979993.606 & 0.012 & 979979.596 & 127.961 \\
\hline 1162 & 36.3596 & 25.4023 & 72.819 & 979954.575 & 0.017 & 979940.558 & 112.855 \\
\hline 1163 & 36.3618 & 25.3877 & 174.667 & 979932.724 & 0.025 & 979918.697 & 122.238 \\
\hline 1165 & 36.3592 & 25.4013 & 76.279 & 979953.423 & 0.025 & 979939.406 & 112.808 \\
\hline 1166 & 36.3596 & 25.4008 & 78.295 & 979952.647 & 0.031 & 979938.63 & 112.615 \\
\hline 1167 & 36.3598 & 25.4094 & 83.007 & 979954.214 & 0.024 & 979940.196 & 115.62 \\
\hline 1168 & 36.3638 & 25.4249 & 119.301 & 979957.26 & 0.027 & 979943.238 & 129.515 \\
\hline 1169 & 36.3452 & 25.4249 & 7.194 & 979981.962 & 0.024 & 979967.951 & 121.239 \\
\hline 1170 & 36.3481 & 25.4267 & 40.771 & 979975.161 & 0.029 & 979961.147 & 124.545 \\
\hline
\end{tabular}




\begin{tabular}{|c|cccllll|}
\hline 1171 & 36.3577 & 25.4295 & 108.139 & 979962.054 & 0.023 & 979948.033 & 131.394 \\
1172 & 36.3388 & 25.4438 & 6.1 & 979989.79 & 0.021 & 979975.779 & 129.281 \\
1173 & 36.3407 & 25.4558 & 3.46 & 979990.533 & 0.025 & 979976.522 & 129.047 \\
1174 & 36.3539 & 25.4734 & 3.896 & 979996.732 & 0.026 & 979982.722 & 134.246 \\
1175 & 36.3571 & 25.4447 & 76.548 & 979979.692 & 0.026 & 979965.674 & 139.339 \\
1176 & 36.3666 & 25.4269 & 138.882 & 979954.117 & 0.024 & 979940.093 & 132.171 \\
1178 & 36.3607 & 25.4041 & 13.078 & 979968.997 & 0.023 & 979954.985 & 108.751 \\
1179 & 36.361 & 25.4052 & 22.924 & 979966.522 & 0.03 & 979952.51 & 109.293 \\
1180 & 36.3871 & 25.431 & 4.287 & 979993.457 & 0.025 & 979979.446 & 128.224 \\
1181 & 36.4084 & 25.4 & 52.67 & 979970.592 & 0.026 & 979956.577 & 118.446 \\
1182 & 36.4607 & 25.39 & 155.73 & 979947.675 & 0.015 & 979933.65 & 122.806 \\
1183 & 36.4063 & 25.3967 & 100.58 & 979957.942 & 0.024 & 979943.922 & 120.754 \\
1184 & 36.3874 & 25.4367 & 300.11 & 979924.501 & 0.013 & 979910.462 & 150.503 \\
2000 & 36.4073 & 25.4786 & 34.679 & 979992.918 & 0.005 & 979978.904 & 135.319 \\
\hline mean & 36.3844 & 25.4 & 90.202 & 979965.854 & 0.02 & 979951.835 & 127.356 \\
$\max$ & 36.4768 & 25.4816 & 300.11 & 979996.732 & 0.031 & 979982.722 & 154.669 \\
$\min$ & 36.2446 & 25.2072 & 1.14 & 979924.501 & 0.009 & 979910.462 & 108.751 \\
SDV & 0.057 & 0.0665 & 80.895 & 19.885 & 0.004 & 19.892 & 11.267 \\
\hline
\end{tabular}

